have this very direct relationship to one another-that they are all dependent upon failure of the visual memory. The intelligent exercise of vision is a very complex act of which we have as yet only very imperfect knowledge. To the successful exercise of the function the brain contributes as largely as the eye. The ocular defects in all their multitudinous variety have been studied for many years with great ndustry and success, but the cerebral disorders, which interfere with intelligent vision, have until recent years not met with the attention they merit.

Increasing knowledge of the cerebral derangements of vision, based on clinical and pathological observation, makes it clear that we must carefully distinguish between the visual perceptive centre and the visual memory centre. The perceptive centres situated in the occipital lobes, chiefly in the neighbourhood of the cuneus and calcarine fissure, enable us to have conscious perception of objects as occupying a definite position in the visual fields. Derangements of this visual centre are evidenced by defects in the visual field, which have all been carefully studied. But the act of vision is infinitely more complex than the simple perception of an object as occupying a particular position in the visual field. It involves complex judgments and, above all, a constant comparison of present visual impressions with the vast series of past visual impressions, the accumulated riches of our life experience which are stored up in a special cerebral area, the visual memory centre, occupying the supra-marginal and angular gyri. Derangements of this centre are evidenced by the various forms of mind-blindness. The objects are distinctly seen, but they convey no information to the individual since they are no longer recognised by him. Word-blindness and loss of memory for places and objects are all simple varieties of mind-blindness. Clinical experience and pathology teach that wordblindness or loss of the visual memory of word symbols is due to a lesion in the visual memory centre on the left side of the brain. In most cases of word-blindness there is no interference with the other forms of visual memory such as those of places, of objects, of form and colour. When there is complete mind-blindness involving the loss of all forms of visual memory it is probable that there is a bilateral lesion involving the centres on both sides of the brain. In the present case there is nothing approaching to complete mind-blindness; but the loss of memory for places and the striking failure of that necessary for his employment, in addition to the peculiar derangement of the visual memory for letters, suggest the probability of some impairment of the functional activity of the right as well as the left centre. Nor is this supposition improbable when we consider that many of the nerrous disorders due to alcoholism are bilateral, such as amblyopia and the ocular paralyses which are sometimes met with. It is a familiar fact that while alcoholism has a hurtful influence on the whole nervous system its toxic influence may manifest itself by attacking specially some particular nerve or group of nerves or even some particular bundle of nerre fibres. That it also impairs the activity of the cerebral centres as a whole is frequently shown by a general failure of the mental powers, but here it also may exert its baneful influence on some special cerebral area and produce a temporary cessation of activity or de. rangement of that particular centre. M. Michel Delines in an interesting stud $y^{11}$ has called special attention to this fact. In the case under consideration the visual memory centres seem to have been specially attacked or, as suggested by Professor Berlin, their connecting fibres.

The derangements of these visual memory centres bave met with comparatively little study and are not generally known, therefore the vast majority of such cases escape observation and hence our comparatively scanty records regarding them. This is my apology for discussing the subject again at such a brief interval and at the risk of some repetition. The case just recorded forms an interesting sequel to my last and gives a clinical picture of another form of derangement of the visual memory. In this case the symptoms were only transient, being due to functional derangement caused by toxic influences; but in the vast majority of cases this form of visual derangement is a symptom of grave organic disease of the brain. Most important of all, it is a focal symptom pointing to disease of a particular area of the brain and it has already been used with success as a localising symptom in cases where surgical interference was indicated.

Glasgow. 11 M. Michel Delines: Les Alcooliqueq, Psychologie et Physiognomonie. Michel Delines: Les Alcooliques, Psychologie et Pl

\section{GANGRENE OF THE LUNG; INCISION AND DRAINAGE; RECOVERY.1}

\author{
BY F. B. WILLMER PHILliPS, M.B. OxON,, \\ AND \\ W. GIFFORD NASH, F.R.C.S. ENG.
}

A TALL, spare man aged thirty six years, of active habits, on April 6th, 1892, caught a chill at a dance, and on the following day, during a long bicycle ride, was attacked by cold shivers. He kept at work until April 9th, on which day he was seen in bed complaining of acute pain on the right side of his chest which was increased by movement, but no physical signs were detected. The temperature was raised two or three degrees. There was no cough or expectoration. He returned to work on April 13th, and, except during the Easter holiday, kept at work nntil April 23rd, when, owing to weakness, chills, night sweats, and cough, he was obliged to give up. The irritating cough suggested laryngeal disease, for which he was sent to Mr. Charters Symonds, who found nothing beyond a little congestion of the larynx. After this be became gradually worse, he lost weight, and his breath became offensive. On May 9th a patch of dulness over the fifth rib in the right anterior axillary line appeared, with deficient breath sounds. Mr. Nash saw the patient on May 12th, when the signs present were pain in the right hypochondrium, a patch of dulness which corresponded to the middle lobe of the right lung and over which there was absence of breath sounds, deficiency of vocal fremitus and resonance, and presence of whispering pectoriloquy. A long hypodermic needle was introduced in the sixth space and slipped through firm resisting material into some soft substance; it drew off stinking air, blood, pus, and fatty débris. The next day Mr. Nash made an incision over the sixth space in the midaxillary line and resected one and a half inches of the sixth rib. The parietal and visceral layers of the pleura, which were much thickened and adherent at this spot, were cut through and a grooved director was pushed on into a gangrenous cavity. The opening was enlarged with dressing forceps and the index finger was introduced its whole length into a cavity with sloughing walls. This was irrigated, and much softened tissue was removed by firm rubbing with pieces of sponge. A large drainage-tube was inserted, and daily irrigation with a solution of boracic acid or perchloride of mercury was practised. The cough and fotor disappeared for a time, but soon returned. The temperature, too, varied considerably, and the patient continued to have night $\mathrm{s}$ weats and to lose flesh. There was much dulness around the wound, and it was thought that there might be some undrained collection of pus. Accordingly on June 10th two inches of the seventh and ejghth ribs were removed in the region of the posterior axillary line and the lung was explored in every direction with a needle and syringe. No pus could be found. After this the temperature continued to oscillate, but the patient held his ground and took nourishment well. On Aug. 4th there was still a copious and offensive discharge. Irrigation of the cavity produced coughing and expectoration of the irrigating fluid. On the 21 st he had a severe rigor with great collapse. On Sept. 11th there was a discharge of a considerable collection of pus, which was followed by another rigor. On the 21st he sat up out of bed for the first time. On Oct. 16th there was another large discharge of pus, and on the $29 \mathrm{th}$ another rigor. On Nov. 21st he was removed to his father's house at Louth, Lincolnsbire, where he was attended by Mr. Myers, to whose incessant care and skilful treatment his ultimate recovery was in a large measure due. On Jan. 7th, 1893, he had another rigor and a few days later it was noticed that there was an increase of dulness in the right lung. On May and Mr. Myers reported a great improvement and on the $13 \mathrm{th}$, a year after the first operation, the tube was removed for good. The irrigation was gradually left off and the wound was quite healed by the end of July. On June 24th he expectorated about six ounces of bright frothy blood, and hamoptysis has occurred occasionally down to the present time. When seen in September of this year (1896) the patient looked fairly well but thin. His

Abstract of a paper read before the Dedford Medical Society on Oct. 29 th, 1896 
weight was a stone less than his previous maximum. $\mathrm{He}$ was able to ride a bicycle thirty miles in an afternoon and walk eight miles at a stretch. The chest showed considerable recession of the wall on the right side. There was a small area of dulness over the region of the scar. The breath sounds were normal except at this spot, where they were faint. He complained of some irritation of the throat, but there was nothing in the pharynx or larynx to account for this. The attacks of hæmoptysis of which he complained probably arose from a vessel in the original focus of disease.

Remarks.-On referring to several published cases of gangrene of the lung it was found that in at least two cases physical examination revealed nothing, and in others the physical signs were quite out of proportion to the severity of the symptoms. Again, it has been noticed that the local signs developed some time after the commencement of the illness. These two points are of special interest in reference to this case. The pathognomonic symptom in every case of gangrene of the lung is expectoration of foetid sputum. In this case the indications for operation were the distressing cough, with foetid breath and sputum, night sweats, and shiverings, with progressive loss of flesh and strength. The results of aspiration made the presence of gangrene certain, and the presence of adhesions made the operation comparatively simple and safe. Surgical treatment of this affection gives very encouraging results. The mortality, if treated medically, is 75 to 80 per cent. M. Reclus, in his address at the French Surgical Congress of 1895, gives statistics from various sources of 117 cases operated on between 1879 and 1895, with 68 recoveries-i.e., a mortality of 42 per cent. His own statistics between 1885 and 1895 give 14 cases with 12 recoveries-i.e., a mortality of less than 15 per cent. It is said to be advisable to defer operation so long as there are no signs of septic absorption, until the lung is breaking down and until adhesions are present.

Bedford.

\section{T By C. DANIELS, M.B. CANTab.}

Two specimens of a tapeworm of a species allied to Tænia Madagascariensis were found here in an adult male aboriginal Indian loose in the jejunum. One of the specimens was cut into three pieces in opening the bowel; the other, with the exception of the head, was intact. They were both dead and the heads were not found after a careful examination, the search being difficult both on account of their small size and of the presence of an enormous number of ankylostomata. The length of the uncut specimen was nine inches $(23 \mathrm{~cm}$. $)$, regularly increasing in size and length of segments from above downwards. The first segment was $0.37 \mathrm{~mm}$. in breadth and 0.07 in length, whilst the $50 \mathrm{th}$ was $0.8 \mathrm{~mm}$. in breadth and $0.2 \mathrm{~mm}$. in length. About the 150 th the segments were $1.2 \mathrm{~mm}$. in breadth and $04 \mathrm{~mm}$. in length, and male and female organs of generation were here plainly visible. About the 250th the breadth and length were practically the same $-1.7 \mathrm{~mm}$. - and in the remaining segments the increase was almost entirely in length, the terminal segments being slightly over $3 \mathrm{~mm}$. long and little more than half that in width. In all there were in the specimen about 320 segments. The most marked peculiarity of the worm and that in which its only resemblance to the Tænia Madagascariensis exists is the arrangement in the ripe segments of the eggs in balls or masses visible to the naked eye. These were from 0.25 to $035 \mathrm{~mm}$. in diameter, and there were from seventy to ninety in each proglottis. They were enclosed in a fibrillated capsule continuous with a similar but softer and more gelatinous matrix, in which were embedded a number of separate embryos about $0.015 \mathrm{~mm}$. in diameter, with distinct protuberance surrounded by three pairs of slender but long hooklets. In the first 60 segments there were no recognisable reproductive organs, but about the 150th the testes, ovaries, penis, and genital canals could be easily made out. The genital pores barely projected and were all situated on the same side; in the ripe segments they could not be detected. The illustrations are enlarged about nine times, and also one (Fig. 4) more highly magnified showing as points the eggs in the egg masses.

The main differences in these specimens and those descriked by Davaine are the size of the worm, which he

estimated at $8 \mathrm{~cm}$, the number of segments 100 , here 320 , and their shape (square), all of which might be due to the worm being contracted, and also from the imperfect condition of the specimens the estimations may have been erroneous. The smallest segment he examined was $2.2 \mathrm{~mm}$. in breadth and $0.8 \mathrm{~mm}$. in length, and had no recognisable reproductive organs, whilst they are easily visible (vide Fig. 2) even in a photograph in these specimens in much smaller segments-1.2 $\mathrm{mm}$. by $04 \mathrm{~mm}$. The egg

FIG. 1 .

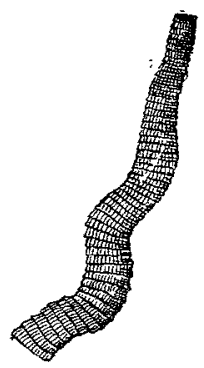

Portion of worm just below the head.
FIG. 2.

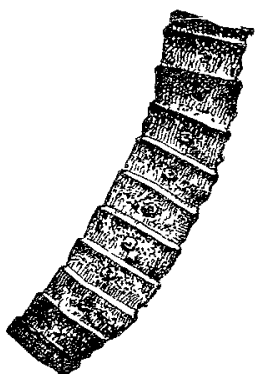

Portion of worm at about 150 th segment showing $g$ enital pores.

masses also in mine are smaller, from 0.25 to $0.35 \mathrm{~mm}$. in diameter, whilst in Davaine's the are from 0.3 to $0.5 \mathrm{~mm}$., and they are composed of substances gelatinous rather than glutinous. The numper in each proglottis, both in unripe and mature seoments, was from 70 to 90 , whilst in Davaine's it was from 120 to 150, and the number of eggs in each I believe to be under 100. As far as

\section{FIG. 3.}

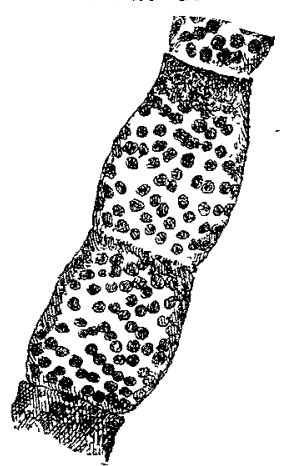

Portions of worm between segments 300-320 showing egg masses.

I can gather there has never been any direct communication between Madagascar and British Guiana, though in slave times and subsequently there was a good deal between British Guiana and the West Coast of Africa. The occurrence of the worm in an aboriginal, though these mix to some extent with imported races, points to the source being indigenous; but as their diet comprises most animal foods, from grasshoppers to monkeys, it would be impossible to readily identify the intermediate host. Considering every thing it therefore seems probable that the specimens described are of a species allied to, rather than identical with, the Tænia Madagascariensis.

George Town, British Guiana.

Sunday IECTURE SOcIETY. - Owing to an adverse balance-sheet and some difficulty in obtaining a suitable hall for its lectures the Sunday Lecture Society has been compelled to postpone the commencement of this season's programme. The society has, however, secured its old quarters in St. George's Hall, Langham-place, and will hold a short course of twelve lectures on Sunday afternoons at four o'clock, commencing on Nov 29th, when Mr. Arthur Diósy will lecture on "The Subjects of the Sultan." Among the other lectures will be one on the New Photography by Mr. Richard Kerr on Jan. 3rd, to be followed by another on Artificial Light by Professor Vivian B. Lewes, It is hoped that the public will so patronise the lectures as to place the finances of the society in a more satisfactory position at the end of the season. It would be a pity that the premier Sunday Lecture Society, after twenty-seven years of such good work, should have to close its doors for want of support. 